\title{
Using probiotics in freshwater larviculture
}

\author{
Barbara Kazuń, Krzysztof Kazuń
}

Received - 13 March 2019/Accepted - 08 September 2019. Published online: 30 September 2019; OInland Fisheries Institute in Olsztyn, Poland Citation: Kazuń B., Kazuń K. 2019 - Using probiotics in freshwater larviculture - Fish. Aquat. Life 27: 130-135.

\begin{abstract}
Probiotics have become a significant component of aquaculture in recent years. The use of antibiotics is decreasing successively because of their side effects in animals and their negative environmental impact, which is why alternative preventative measures are being sought. Probiotics that are effective in this field are playing increasingly important roles in safeguarding the health of fish and also as growth stimulants. The application of probiotics can help to successfully control the occurrence of disease in hatcheries, increase larval survival, and improve rearing parameters thanks to which the number of required brood-fish, which are expensive to maintain, can be reduced.
\end{abstract}

Keywords: eco-friendly, growth, larval feed, larviculture, probiotics, survival

\section{Introduction}

Hatchery and larviculture are very significant parts of aquaculture, in which the production of material for stocking and pond culture is playing an increasingly important role. The most frequently cultured fish species in Poland include common carp, Cyprinus carpio L. and rainbow trout, Oncorhynchus mykiss (Walbaum), but there is growing demand for other species that are common in pond culture and also

B. Kazuń, K. Kazuń [

Department of Fish Pathology and Immunology in Żabieniec, Inland

Fisheries Institute in Olsttyn, Poland

e-mail: k.kazun@infish.com.pl those that are particularly ecologically valuable. Consequently, it is increasingly important to produce stocking material for lakes and rivers and for pond culture that are more resistant to disease, utilize feed better, and have faster growth rates. However, the occurrence of disease under culture conditions can require the application of antibiotics, which often leads to drug resistant strains, and the long-term application of antibiotic therapies suppresses fish immune systems and hinders effective treatment. This is why innovative solutions are constantly being sought as alternatives to antibiotics that simultaneously have a positive impact on the environment and the well-being of animals.

Biological methods for protecting plants and animals have been used in various fields of agriculture, both in plant culture and animal husbandry, for many years, and probiotics and synbiotics are enjoying growing interest from scientists and are the subject of study around the world. Not without significance is the fact that, inter alia, lactic acid bacteria (LAB), which exhibits probiotic characteristics, has the status of generally recognized as safe (GRAS), which means that it is considered to be safe for consumer health. The available scientific literature indicates that applying LAB in aquaculture can limit the occurrence of fish diseases and reduce the quantities of antibiotics administered (Gatesoupe 1999). Probiotics used in aquaculture have wide ranging impacts, but above all else they stimulate elements of 
the immune system to increase resistance to disease while simultaneously improving growth parameters and water quality. Probiotic bacteria for animals reared in aquaculture can be added directly to the water or with the feed, either live or granulated. It is also possible to apply one or several strains of probiotic bacteria simultaneously or together with prebiotics or synbiotic immunostimulators; however, there must not be any antagonistic interactions among the microorganism components of probiotics. Studies suggest that probiotics containing many strains of probiotic bacteria are more effective than single-strain probiotics (Chapman et al. 2011). The origin of probiotic bacteria can be endogenous, such as strains isolated from the gastrointestinal tracts of healthy fish, or exogenous that are derived from warm-blooded animals, from the aquatic environment, or from dairy products. In the case of the last category of probiotics, tests should be carried out to verify the possibility of the bacteria adapting to and surviving in the specific gastrointestinal tract conditions of fish, where they might exhibit effective probiotic activity (Wanka et al. 2018).

Scientific studies conducted to date indicate that administering probiotic bacteria that can colonize the fish gastrointestinal tract protects them from pathogens multiplying and stabilizes microorganism populations in gastrointestinal tracts (Ringo et al. 1995, Gatesoupe 1999, Verschuere et al. 2000, Mohapatra et al. 2012). Stabilizing gastrointestinal tract microflora participates in protecting fish against pathogens entering the gastrointestinal tract; one of the main natural defenses of bodies is a properly functioning gastrointestinal tract with fully formed intestinal flora. In this stabilized microbiome, there should be sufficient proportions of bacteria that are antagonistic against pathogenic strains. After colonization, probiotic bacteria can act on the immune system through gut-associated lymphoid tissue (GALT). However, unlike mammals, fish do not have organized lymph structures, such as Peyer's patches, and they also do not produce IgA antibodies or M cells. These functions are performed by dispersed lymphoid cells, macrophages, granulocytes, and IgM antibodies. Scientific research results confirm that probiotics stimulate immune system functions by activating various GALT cells (Piccietti et al. 2009).

Probiotics and synbiotics are also administered to cultured fish to stimulate digestive enzymes and increase the digestibility and assimilability of nutritional substances such as lipids, protein, and carbohydrates by increasing the activity of lipase, protease, and amylase, respectively (Tovar et al. 2002, Askarian et al. 2011, Mohapatra et al. 2012, Wu et al. 2012). When vegetable proteins are used fish feed, anti-nutritive substances render nutrient utilization difficult, and probiotic bacterial nutritional supplements can mitigate these negative effects (Wanka et al. 2018). Some probiotic bacteria can also synthesize vitamins $B$ and $K$ and nutrients such as unsaturated fatty acids and their precursors, which have positive effects on the development of the fish nervous system during early ontogenesis, and they can prevent spinal curvatures (Verschuere et al. 2000, Lamari et al. 2013). In general, adding probiotic bacteria to fish diets promotes better food assimilation, and it enriches diets with a number of substances of bacterial origin thus contributing to increased body weight and accelerated growth rates and development.

From the perspective of protecting fish health, administering probiotic bacteria to many species reared in culture conditions such as common carp, rainbow trout, Atlantic salmon, Salmo salar L., European eel, Anguilla anguilla (L.), Nile tilapia, Oreochromis niloticus (L.), and European perch, Perca fluviatilis L. permits controlling a range of dangerous pathogens such as Aeromonas salmonicida, Yersinia ruckeri, Vibrio anguillarum, Aeromonas hydrophila, and Edwardsiella tarda (Chang and Liu 2002, Brunt et al. 2007, Harikrishnan et al. 2010, Sharifuzzaman and Austin 2017).

\section{Selecting probiotic bacteria to administer in larviculture}

Numerous scientific articles report on the use of probiotics in aquaculture in various species of 
cultured fish and crustaceans (Newaj-Fyzul et al. 2007, Kumar et al. 2008, Harikrishnan et al. 2010, Das et al. 2013). Current research focuses primarily on administering probiotics to juveniles and adults so there is not much data available on administering probiotics and synbiotics in freshwater fish larviculture, because manipulating their microbiomes has not yet piqued the interest of scientists.

The gastrointestinal microflora of freshwater fish is dominated by Gram-negative bacteria (Aeromonas spp., Pseudomonas spp. Flavobacterium spp., Acinetobacter spp.), and, it has been demonstrated that environmental factors can affect it (Izvekova et al. 2007).

Selecting strains for larviculture that have the most favorable probiotic properties should be done comprehensively. In addition to favorable growth properties, the microorganisms chosen should have desirable functional characteristics including the ability to adhere to the gastrointestinal mucosa, and they should produce antibacterial and antibiotic compounds.

Probiotic bacteria should multiply in the intestine of fish larvae quickly enough to compensate for any deficits stemming from frequent gastric evacuation. The ability to adhere to the intestinal mucosa is an individual characteristic of different bacterial strains that is indispensable in the colonization process, because properties affecting the strength of adhesion determine how long the probiotic is in contact with fish (Collado et al. 2008). Most fish larvae hatch with sterile, immature digestive systems that are initially inhabited by bacteria inhabiting egg surfaces and the water (Ringo and Brikbeck 1999). Gastrointestinal colonization increases with exogenous feeding, and, over time, the fish gastrointestinal microbiome resembles the microfloral composition of natural food. Therefore, the timing of administering probiotic bacteria is crucial, because administering them in early larval stages facilitates colonization and survival among autochthonous intestinal microflora. One of the specificities the larval fish gastrointestinal environment is that it is poor in nutrients, especially glucose, which probiotic bacteria require for growth (Ringo et al. 1995). This, combined with frequent gastric evacuation mentioned previously, render choosing appropriate strains difficult. By attaching to receptors located in the gastrointestinal mucosal epithelium, probiotic bacteria inhibit other strains from colonizing it, including pathogenic strains. Probiotic bacteria also produce metabolites with antimicrobial properties such as organic acids, bacteriocins, and hydrogen peroxide, which also inhibit the growth of pathogenic bacteria. This is how probiotics compete with pathogens for adhesion receptors, nutrients, and oxygen, and they also produce antimicrobial substances, reduce the possibilities pathogenic colonization, and inhibit their multiplication (Verschuere et al. 2000).

Probiotic microorganisms should also exhibit enzymatic activity that facilitates digestion and food assimilation. All these features of potentially probiotic bacteria acting simultaneously and synergistically mean that they are formidable competitors for opportunistic bacteria colonizing the gastrointestinal tract, because the longer the probiotics remain in the intestinal lumen, the greater their potential is to have a healthy impact on larvae.

The most common way to administer probiotics in larviculture is through bioencapsulation, i.e., enriching brine shrimp nauplii (Artemia sp.) or rotifers with LAB and other bacteria (Gatesoupe 1994, Planas et al. 2006). Brine shrimp are an important food in the culture of juvenile stages of freshwater fish thanks to their small size, slow movement in the water, ease of use, and appropriate nutritional composition. They are also very useful as a vector of probiotic bacteria to larval fish and facilitate the effective administration of probiotics. The quantity of bacteria administered in this way should not, however, affect the palatability and viability of the food organisms, because adding excessive amounts of probiotic bacteria can result in the larval fish not being interested in the food (Nicolas 1989). For some species, such as some salmonids, the larvae of which are larger and have more developed gastrointestinal tracts, probiotics can be administered with granulated feed. 
The length of time during which probiotic bacteria are administered is also important, and it should be adapted to the developmental stage of the fish, the density of the bacterial suspension applied, and the type of larviculture in which it is administered. Short-term administration might not ensure gastrointestinal tract colonization and not improve larval survival, while long-term probiotic administration can lead to the tolerance of a given probiotic, or it can even have an immunosuppressive effect. Good effects can be achieved by administering probiotics for at least two weeks, with a break from applying conventional feeding (Bricknell and Dalmo 2005). A well-chosen strategy of immunostimulation should ensure a resting phase for the immune system, which is then later stimulated again. It is advisable to use probiotic preparations during sensitive periods for the larvae that can weaken their immunity, such as yolk sac depletion or the beginning exogenous food consumption. Immunomodulation of the immune system should ensure increased survival of larval fish by stimulating the developing immune system until the adaptive immune response develops.

\section{Probiotics in freshwater larviculture}

The embryos of terrestrial mammals develop within the amniotic cavity, while fish larvae are released directly into the water at an early stage of individual development, when their digestive and immune systems are not yet fully developed. Manipulating the intestinal microflora of fish in early ontogenetic stages, when mortality is high, can improve larval survival and food use, and it can have a positive effect on culture indexes. Enyidi and Onuoha (2016) report faster growth rates in North African catfish larvae (Clarias gariepinus (Burchell)) that were fed feed supplemented with a mixture of probiotic bacteria (Lactobacillus acidophilus, Lactobacillus bulgaricus, and Bacillus subtilis). The results of this study suggested that the addition of bacteria could also cause increased digestibility and better food utilization. Jha et al. (2015) also noted that the addition of probiotics improved survival and accelerated growth rates in larval roho labeo, Labeo rohita (Hamilton). Better growth and higher larval survival rates were also observed after supplementing beluga, Huso huso (L.) and Persian sturgeon, Acipenser persicus Borodin diets with Pediococcus acidilactici (Taridashti et al. 2017, Zare et al. 2017).

Bacteria of the genus Bacillus are of the most interest to aquaculture (Newaj-Fyzul et al. 2007, Kumar et al. 2008, Das et al. 2013). Research on administering the commercial probiotic Protexin, which contains Bacillus bacteria, to larval rainbow trout indicated there was faster larval growth, lower feed conversion ratios, and higher protein absorption (Adineh et al. 2013). Similar effects were observed in larval silver carp, Hypophthalmichthys molitrix (Val.) that were fed a blend of probiotic Bacillus bacteria (Bacillus licheniformis, Bacillus circulans, and Bacillus polymixa) and baker's yeast (Adineh et al. 2011). Administering a bacterial mixture of $B$. licheniformis, B. subtilis, and Bacillus pumilus had a positive effect on the growth, survival, lysozyme activity, and total immunoglobulin in larval European perch (Mandiki et al. 2011). Increased survival rates in larval Danube sturgeon, Acipenser gueldenstaedtii Brandt \& Ratzeburg were observed after dietary supplementation with the probiotic Bifitrilak (Bifidobacterium spp. and Lactobacillus spp.; Alamdari et al. 2013). Bacillus, Pseudomonas, Acinetobacter, and Flavobacterium species isolated from hatchery systems were reported to have had positive effects on the hatching and survival of larval North African catfish (Ariole and Okpokwasili 2012).

The effects of administering probiotic bacteria to ornamental freshwater larvae such as zebra danio, Danio rerio (Hamilton) and rosy barb, Pethia conchonius (Hamilton) have also been investigated, and results indicated that probiotics successfully modified intestinal microflora and reduced the number of pathogenic intestinal bacteria (Divya et al. 2012, Isamma et a. 2014). The addition of $B$. licheniformis and Bacillus latrospore bacteria and the yeast Saccharomyces cerevisiae to the diet of larval guppy, Poecilia reticulate Peters that were experimentally infected with Ichthyophthirius multifiliis 
ciliates positively affected their survival (Sahandi et al. 2013). Maradonna et al. (2013) demonstrated that dietary Lactobacillus rhamnosus bacterial supplementation had a positive effect on the formation of larval zebra danio skeletons by stimulating the expression of genes associated with ossification and inhibiting sclerostin, an inhibitor of osteoblast activity. The probiotic $L$. rhamnosus also had a positive effect on hormonal control, stimulating follicular maturation and inhibiting naturally occurring apoptosis in ovaries thereby increasing zebra danio spawner fertility (Gioacchini et al. 2010, Carnevali et al. 2013).

Probiotics have become an important part of aquaculture in recent years. The use of antibiotics is gradually decreasing because of their side effects in animals and their negative environmental impact, while the amount of research focused on identifying alternative preventive measures is increasing. Probiotics and immunostimulators are playing increasingly important roles in protecting fish health and as growth stimulators. Administering probiotics can help to effectively control the occurrence of diseases in hatcheries, increase larval survival, and improve breeding indexes, which will help reduce the required number of brood-fish, which are costly to maintain.

Author contributions. Both authors contributed materials and wrote the draft manuscript, read and approved the final manuscript.

\section{References}

Adineh H., Jafaryan H., Faramarzi M., Boloki M.L., Jamali H., Alizadeh M. 2011 - The effects of mixture commercial live bakers' yeast and probiotic bacillus on growth and feeding performance and survival rate of silver carp (Hypophthalmichthys molitrix) larvae via bioencapsulated Artemia urmiana nauplii - AACL Bioflux 4: 430-436.

Adineh H., Jafaryan H., Sahandi J., Alizadeh M. 2013 - Effect of Bacillus spp. probiotic on growth and feeding performance of rainbow trout (Oncorhynchus mykiss) larvae Bulg. J. Vet. Med. 16: 29-36.
Alamdari H., Dolganova N.V., Ponomarev S.V. Vinnov A.S. 2013 - Results of starter diet development for sturgeon larvae by use of spart protein hydrolysate and probiotic „Bifitrilak” - Fishing Industry 2: 172-177.

Ariole C.N., Okpokwasili G.C. 2012 - The effect of indigenous probiotics on egg hatchability and larval viability of Clarias gariepinus - Ambiente \& Aqua - An Interdisciplinary Journal of Applied Science 7: 81-88.

Askarian F., Kousha A., Salma W., Ringo E. 2011 - The effect of lactic acid bacteria administration on growth, digestive enzyme activity and gut microbiota in Persian sturgeon (Acipenser persicus) and beluga (Huso huso) fry Aquacult. Nutr. 17: 488-497.

Bricknell I., Dalmo R.A. 2005 - The use of immunostimulants in fish larval aquaculture - Fish Shellfish Immunol. 19: 457-472.

Brunt J., Newaj-Fyzul A., Austin B. 2007 - The development of probiotics for the control of multiple bacterial diseases of rainbow trout, Oncorhynchus mykiss (Walbaum) - J. Fish Dis. 30: 573-579.

Carnevali O., Avella M.A., Gioacchini G. 2013 - Effects of probiotic administration on zebrafish development and reproduction - Gen. Comp. Endocrinol. 188: 297-302.

Chang C.I., Liu W.Y. 2002 - An evaluation of two probiotic bacterial strains, Enterococcus faecium SF68 and Bacillus toyoi, for reducing edwardsiellosis in cultured European eel, Anguilla anguilla L. - J. Fish Dis. 25: 311-315.

Chapman C.M.C., Gibson G.R., Rowland I. 2011 - Health benefits of probiotics: are mixture more effective than single? - Eur. J. Nutr. 50: 1-17.

Collado M.C., Meriluoto J., Salminem S. 2008 - Adhesion and aggregation properties of probiotic and pathogen strains - Eur. Food Res. Technol. 226: 1065-1073.

Das A., Nakhro K., Chowdhury S., Kamilya D. 2013 - Effects of potential probiotic Bacillus amyloliquifaciens FPTB16 on systemic and cutaneous mucosal immune responses and disease resistance of catla (Catla catla) - Fish Shellfish Immunol. 35: 1547-1553.

Divya K.R, Isamma A., Ramasubramanian V., Sureshkumar S., Arunjith T.S. 2012 - Colonization of probiotic bacteria and its impact on ornamental fish Puntius conchonius - J. Envirol. Biol. 33: 551-555.

Enyidi U.D., Onuoha J.U. 2016 - Use of probiotics as first feed of larval African catfish Clarias gariepinus (Burchell 1822) - Annu. Res Rev. Biol. 9: 1-9.

Gatesoupe F.J. 1994 - Lactic acid bacteria increase the resistance of turbot larvae, Scophthalmus maximus, against pathogenic Vibrio - Aquat. Living Resour. 7: 277-282.

Gatesoupe F.J. 1999 - The use probiotics in aquaculture Aquaculture 180: 147-165.

Gioacchini G., Maradonna F., Lombardo F., Bizzaro D., Olivotto I., Carnevali O. 2010 - Increase of fecundity by probiotic administration in zebrafish (Danio rerio) Reproduction 140: 953-959. 
Harikrishnan R., Balasundaram C., Heo M.S. 2010 - Potential use of probiotic- and triherbal extract-enriched diets to control Aeromonas hydrophila infection in carp - Dis. Aquat. Organ. 92: 41-49.

Isamma A., Divya K.R., Ramasubramanian V., Arunjith T.S., Krishnakumar V., Sureshkumar S. 2014 - Studies on probiotics administration and its influence on gut microflora of ornamental fish Brachydanio rerio larvae Int. J. Curr. Microbiol. App. Sci. 3: 336-344.

Izvekova G.I., Izvekov E.I., Plotnikov A.O. 2007 - Symbiotic microflora in fishes of different ecological groups - Biol. Bull. 34: 610-618.

Jha D.K., Bhujel R.C., Anal A.K. 2015 - Dietary supplementation of probiotics improves survival and growth of Rohu (Labeo rohita Ham.) hatchling and fry in outdoor tanks - Aquaculture 435: 475-479.

Kumar R., Mukherjee S.C., Ranjan R., Nayak S.K. 2008 Enhanced innate immune parameters in Labeo rohita (Ham.) following oral administration of Bacillus subtilis Fish Shellfish Immunol. 24: 168-172.

Lamari F., Castex M., Larcher T., Ledevin M., Mazurais D., Bakhrouf A., Gateusoupe F.J. 2013 - Comparison of the effects of the dietary addition of two lactic acid bacteria on the development and conformation of sea bass larvae, Dicentrarchus labrax, and the influence on associated microbiota - Aquaculture 376-379: 137-145.

Mandiki S.N.M., Milla S., Blanchard G., Djonkack T., Tanascaux S., Kestemont P. 2011 - Effects of probiotic bacteria on growth parameters and immune defence in Eurasian perch Perca fluviatilis L. larvae under intensive culture conditions - Aquac. Res. 42: 693-703.

Maradonna F., Gioacchini G., Falcinelli S., Bertotto D., Radaelli G., Olivotto I., Carnevali O. 2013 - Probiotic supplementation promotes calcification in Danio rerio larvae: a molecular study - PloS One. 8: e83155.

Mohapatra S., Chakraborty T.,. Prusty A., Das P., Paniprasad K., Mohanta K. 2012 - Use of different microbial probiotics in the diet of rohu, Labeo rohita fingerlings: effects on growth, nutrient digestibility and retention, digestive enzyme activities and intestinal microflora Aquacult. Nutr. 18: 1-11.

Newaj-Fyzul A., Adesiyun A.A., Mutani A., Ramsubhag A., Brunt J., Austin B. 2007 - Bacillus subtilis AB1 controls Aeromonas infection in rainbow trout (Oncorhynchus mykiss, Walbaum) - J. Appl. Microbiol. 103: 1699-1706.

Nicolas J.L., Robic E., Ansquer D. 1989 - Bacterial flora associated with a tropical chain consisting of microalgae, rotifers and turbot larvae: influence of bacteria on larval survival - Aquaculture 83: 237-248.
Piccietti S., Fausto A.M., Randelli E., Carnevali O., Taddei A.R., Buonocore F. 2009 - Early treatment with Lactobacillus delbrueckii strain induces an increase in intestinal T-cells and granulocytes and modulates immunerelated genes of larval Dicentrachus labrax (L.) Fish Shellfish Immunol. 26: 368-376.

Planas M., Pérez-Lorenzo M., Hjelm M., Gram L., Fiksdal I.U., Bergh Ø., Pintado J. 2006 - Probiotic effect in vivo of Roseobacter strain 27-4 against Vibrio (Listonella) anguillarum infections in turbot (Scophthalmus maximus L.) larvae - Aquaculture 255: 323-333.

Ringo E., Birkbeck T.H. 1999 - Intestinal microflora of fish larvae and fry - Aquac. Res. 30: 73-93.

Ringo E., Strom E., Tabachek J.A. 1995 - Intestinal microflora of salmonids: a review - Aquac. Res. 26: 773-789.

Sahandi J., Jafaryan H., Moradi P., Tadiri Ch. 2013 - Effect of in-feed probiotic blend on growth performance and infection resistance of the guppy (Poecilia reticulata) - Bulg. J. Vet. Med. 16: 243-250.

Sharifuzzaman S.M., Austin B. 2017 - Probiotics for disease control in aquaculture - In: Diagnosis and control of diseases of fish and shellfish (Eds) B. Austin, A. Newaj-Fyzul, John Wiley \& Sons Ltd.: 189-222.

Taridashti F., Delafkar K., Zare A., Azari-Takami G. 2017 Effects of probiotic Pediococcus acidilactici on growth performance, survival rate, and stress resistance of Persian sturgeon (Acipenser persicus) - J. Appl. Aquac. 29: 3-4.

Tovar D., Zambonino J., Cahu C., Gatesoupe F., Vázquez-Juárez R., Lésel R. 2002 - Effect of live yeast incorporation in compound diet on digestive enzyme activity in sea bass (Dicentrarchus labrax) larvae Aquaculture 204: 113-123.

Verschuere L., Rombaut G., Sorgeloos P., Verstraete W. 2000 - Probiotic bacteria as biological control agent in aquaculture - Microbiol. Mol. Biol. Rev. 64: 655-671.

Wanka K.M., Demerau T., Costas B., Krueger A., Schulz C., Wuertz S. 2018 - Isolation and characterization of native probiotics for fish farming - BMC Microbiology 18: 119.

Wu Z., Feng X., Xie L., Peng X., Yuan J., Chen X. 2012 Effect of probiotic Bacillus subtilis Ch9 for grass carp, Ctenopharyngodon idella (Valenciennes, 1844), on growth performance, digestive enzyme activities and intestinal microflora - J. Appl. Ichthyol. 28: 721-727.

Zare A., Azari-Takami G., Taridashti F., Khara H. 2017 - The effects of Pediococcus acidilactici as a probiotic on growth performance and survival rate of great sturgeon, Huso huso (Linnaeus, 1758) - Iran. J. Fish. Sci. 16: 150-161. 